\title{
Permittivity of a composite of cellulose, mineral oil, and water nanoparticles: theoretical assumptions
}

\author{
P. Żukowski • T. N. Kołtunowicz • K. Kierczyński 1 • P. Rogalski • \\ J. Subocz $\cdot$ M. Szrot $\cdot$ M. Gutten $\cdot$ M. Sebok $\cdot$ J. Jurcik
}

Received: 24 April 2015/Accepted: 20 October 2015/Published online: 27 October 2015

(C) The Author(s) 2015. This article is published with open access at Springerlink.com

\begin{abstract}
The paper presents results of testing permittivity of an oil-impregnated electric pressboard containing water nanoparticles depending on $\mathrm{AC}$ frequency, moisture content level and the temperature of samples. A new method has been developed for converting experimentally obtained frequency dependences of permittivity determined with the frequencydomain spectroscopy (FDS) to the reference temperature of $293 \mathrm{~K}\left(20^{\circ} \mathrm{C}\right)$ using exponential dependence of the relaxation time versus temperature. Activation energy of the permittivity relaxation time has been determined for a moist oil-impregnated electric
\end{abstract}

P. Żukowski - T. N. Kołtunowicz · K. Kierczyński ( $₫)$.

P. Rogalski

Department of Electrical Devices and High Voltages

Technology, Faculty of Electrical Engineering and

Computer Science, Lublin University of Technology, 38a,

Nadbystrzycka Street, 20-618 Lublin, Poland

e-mail: k.kierczynski@pollub.pl

J. Subocz

Department of Electrotechnology and Diagnostics, West Pomeranian University of Technology, 37 Sikorskiego

Street, 70-313 Szczecin, Poland

M. Szrot

Power Engineering Research Centre Ltd., 9 Lotników

Street, 41-949 Piekary Śląskie, Poland

M. Gutten · M. Sebok · J. Jurcik

Department of Measurement and Applied Electrical Engineering, University of Zilina, 1 Univerzitna Street, 01026 Zilina, Slovakia insulation pressboard. It has been established that variations of the moisture content level in a composite of cellulose, mineral oil, and water nanoparticles do not cause any changes in the relaxation time activation energy value, neither in energy states of electrons in potential wells nor in the structure of water nanoparticles. It has been also found that the conversion of experimentally obtained permittivity versus frequency dependences determined with the FDS method to the reference temperature of $293 \mathrm{~K}\left(20{ }^{\circ} \mathrm{C}\right)$ eliminates temperature dependences that occur in characteristics based directly on measurement results. Once the relative permittivity is converted to the reference temperature it is only its dependence on the moisture content level that remains.

Keywords FDS - Electric insulation pressboard · Moisture content · Permittivity · Relaxation time . Activation energy $\cdot$ Reference temperature

\section{Introduction}

For about 100 years, cellulose in the form of paper and pressboard impregnated with insulating oil has been used as a basic insulation material for high voltage power transformers. In a new transformer moisture content in its cellulose insulation does not exceed $0.8 \mathrm{wt} \%$. In the paper-oil insulation of longtime operated power transformers ageing processes occur manifested by the cellulose depolymerization (Jalbert 
et al. 2015; Gilbert et al. 2010) and a gradual increase of the moisture content level. Depolymerization processes result in the precipitation of water molecules directly in the cellulose fibers. Depolymerization also reduces mechanical strength of the cellulose. Another source of the moisture level increase is water that penetrates into the transformer from the outside and gets dissolved in transformer oil. Next, the water is delivered to the cellulose and gets absorbed by it, because moisture better diffuses into cellulose than into the transformer oil. That way, many-year operation of power transformers results in a gradual increase of the moisture content level in the composite cellulose-mineral oil from its initial level of approx. $0.8 \mathrm{wt} \%$ to the level exceeding $5 \mathrm{wt} \%$. As it was mentioned in the paper (Źukowski et al. 2015a), water in cellulose gets precipitated in the form of nanoparticles of approx. $2.32 \mathrm{~nm}$ that contain approx. 220 water molecules. This is consistent with the sufficient condition for the formation of nanoparticles (Pogrebnjak and Beresnev 2012; Pogrebnyak et al. 2014), which is that oil and water do not enter chemical reactions, they are immiscible and the surface tension of water is much higher than that of insulating oil. The effect is that clusters of water molecules assume a shape of balls, which protects the minimum surface energy.

The dominant part of moisture contained in a highvoltage transformer operated for over 20 years is concentrated in the insulation paper and pressboard and its concentration there in is by several orders higher than that in the transformer oil (Oommen 1983).

According to the operative pertinent US standard doubling of the moisture content level in the insulation reduces the insulation lifetime by a half. Additionally, at the moisture content higher than $2.5 \%$ the degradation process accelerates (US Department of the Interior Bureau of Reclamation 2003).

In the majority of long-time operated power transformers mechanical strength of the cellulose remains satisfactory, while the water content can reach levels that can be hazardous for the further reliable failure-free operation.

This means that the water content increase essentially reduces the quality of paper-oil insulation, as well as the transformer reliability and in many cases can be a source of major power transformer breakdowns and large economic losses.
From the viewpoint of safe operation of sealed power transformers, whose inside cannot be accessed, it is important to develop methods to determine the water content level in their cellulose insulation.

Determination of the water content in paper-oil insulation of power transformers is usually performed by means of non-destructive methods, mainly the electrical ones that are based on the analysis of relaxation processes that occur in oil-impregnated cellulose. Those methods fall into two main groups. The first one includes methods based on measurements in the time domain like the return voltage measurement (RVM) (Saha 2003; Dey et al. 2010) and the polarization-depolarization current measurement (PDC) (Saha and Purkait 2004; Wolny and Kedzia 2010), while in the other group there are methods based on measurements using frequency-domain spectroscopy (FDS) (Zhang et al. 2014; Jaya et al. 2013).

In general, the analysis of dielectric relaxation processes in the frequency domain (the FDS method) is based on a number of models, each of them having more or less reliable physical justification.

As a rule, the analysis is based on the Debye's model of dielectric relaxation (Jonscher 1983). The model Debye's is characterized by several features that cannot be confirmed experimentally. For example in the low values area of pulsatance there is a quadratic conductivity versus frequency dependence. Such behavior can be observed only for almost perfect dielectrics such as diamonds (Ralchenko et al. 2012). However, in a moist oil-impregnated pressboard the mentioned dependence is weaker than quadratic (Żukowski et al. 2015b). Another disadvantage of the Debye's model is the decreased permittivity in the square of frequency. Permittivity measurements performed for many insulating materials including impregnated pressboard of a certain water content show that as a rule the mentioned dependencies are weaker. In order to show that the frequency dependence of $\varepsilon^{\prime}$ (relative permittivity) and $\sigma$ (conductivity) can be weaker than quadratic, researchers have developed a number of empirical models (Cole and Cole 1941, 1942; Havriliak and Havriliak 1997).

However, the major flaw of both the Debye's model (Jonscher 1983) and the empirical models (Cole and Cole 1941, 1942; Havriliak and Havriliak 1997) is their assumption that when the electric field frequency 
tends to zero (DC voltage), the conductivity also decreases down to zero. This contradicts all known experimental results that show a specified limiting value (direct current) of conductivity in the ultra-low frequency range. This means that the analysis of relaxation processes dielectric in a composite of cellulose, mineral oil, and water nanoparticles should be made on the basis of models other than those listed above.

In the paper by Żukowski et al. (2014) it has been found that conduction in a moist oil-impregnated pressboard is realized as a hopping exchange of electrons (tunneling) and is determined by the presence of water molecules there. In the papers (Źukowski et al. 2014, 2015a) it was found that in a composite of cellulose, mineral oil, and water nanoparticles, the conductivity results from electron tunneling between potential wells formed by nanodrops of water. The well, from which the electron hops, gets positively charged, while the well into which the electron hops obtains the negative charge. The above brings about an increase of the material permittivity (Zukowski et al. 1991; Zukowski et al. 1997). In the case of polarization caused by the electron tunneling between potential wells, it is the relaxation time $\tau$ that makes an essential parameter of the phenomena. This is the time period from the dipole formation to the return of a hopping electron to the original well wherefrom its hopping has been initiated. The relaxation time value is of a significant impact on both the permittivity and the conductivity resulting from the hopping electron exchange, and on the frequency range, where phenomena occur polarization caused by the hopping electron transfer. Namely, the polarity is present in the area of the pulsation $\omega<1 / \tau$. For the range of the pulsatance $\omega>1 / \tau$ permittivity decreases and strives for the value characteristic for material having no nano-sized potential well.

In the paper by Kołtunowicz et al. (2013), a model of the hopping electron transfer has been presented for direct and alternating current.

The DC and AC hopping electron transfer model has been experimentally verified for semiconductors that include potential wells, and for nanocomposites (see for example Svito et al. 2014).

The objective of the presented study is to analyze relaxation processes relative permittivity $\varepsilon^{\prime}$ of a composite of cellulose, mineral oil, and water nanoparticles based on the mechanism of hopping change transfer between potential wells produced by the nanoparticles of water.

\section{Analysis of the FDS method applied to the permittivity testing for a composite of cellulose, mineral oil, and water nanoparticles}

The FDS method that is a method for testing the AC response of a dielectric liquid-solid insulation of power transformers is based on the analysis of the second Maxwell's equation (generalized Ampere's law) (Landau et al. 1984):

$\oint(\vec{H} \cdot d \vec{l})=\vec{j}_{R}+\vec{j}_{C}$

where $\oint$ integral along a closed path surrounding the current, $H$ vector of the magnetic field strength, $d \vec{l}$ length vector tangent to the integration path, $\vec{j}_{R}$ vector of the conduction current density, $\vec{j}_{C}$ vector of the displacement current density.

In the sinusoidal exciting electric field of the pulsatance $\omega$, the electric field intensity can be written as follows:

$E=E_{0} \sin (\omega \cdot t)$,

where $E$ instantaneous value of the electric field intensity, $E_{0}$ amplitude of the electric field, $\omega=2 \pi f$ pulsatance (angular frequency), $t$ time, $f$ frequency.

The dielectric relaxation analysis is needed the other current density component that is related to the material polarization can be described by the following formula:

$\vec{j}_{C}(\omega)=\frac{\partial \vec{D}}{\partial t}=\omega \cdot \varepsilon^{\prime} \cdot \varepsilon_{0} \cdot \vec{E}_{0} \sin \left(\omega \cdot t-\frac{\pi}{2}\right)$

where $\vec{j}_{C}$ vector of the displacement current density, $\vec{D}=\varepsilon_{0} \cdot \varepsilon \cdot \vec{E}$ vector of the electric field induction, $\vec{E}_{0}$ amplitude of the electric field, $\omega$ pulsatance, $t$ time, $\varepsilon^{\prime}$ relative permittivity, $\varepsilon_{0}$ vacuum permittivity.

Laboratory measurements using the FDS method are the most commonly realized with the application of a parallel-plate capacitor system, for which:

$\varepsilon^{\prime}=\frac{C}{C_{0}}$ 
where $\varepsilon^{\prime}$ relative permittivity, $C$ capacitance of a capacitor with a dielectric, $C_{0}$ capacitance of a vacuum capacitor (so-called geometric capacitance).

Capacitance of the parallel-plate capacitor can be written as follows (Halliday and Resnick 1978):

$C=\frac{\varepsilon^{\prime} \cdot \varepsilon_{0} \cdot S}{d}, \quad C_{0}=\frac{\varepsilon_{0} \cdot S}{d}$

where $S$ capacitor plate area, $d$ dielectric thickness, $\varepsilon^{\prime}$ relative permittivity, $\varepsilon_{0}$ vacuum permittivity.

Relative permittivity $\varepsilon^{\prime}$ describes the dielectric polarizability and in most cases it is a function of frequency, temperature and moisture content.

An analysis of the temperature and moisture effect on the permittivity versus frequency characteristics of a composite of cellulose, mineral oil, and water nanoparticles is very complex. That complexity will be illustrated by using such material characteristics as $\varepsilon^{\prime}(\omega)$ determined based on the experimental data of (Ekanayake et al. 2006; Walczak et al. 2006). Measurements were performed with the FDS method in a parallel-plate capacitor system. Pressboard samples were dried in a vacuum chamber and then soaked with moisture till the predetermined water content level has been obtained. Next, they were impregnated with transformer oil within 6 months. An impregnated sample has been placed between the capacitor metal plates and the whole measuring setup has been immersed in a bath of insulating oil. The container with a measuring capacitor connected to a meter has been placed in a thermostat to maintain the preset measuring temperature. In the papers by Ekanayake et al. (2006) and Walczak et al. (2006) presented details of the preparation of samples for testing and the course of the study.

\section{Permittivity analysis for a composite of cellulose, mineral oil, and water nanoparticles}

A preliminary analysis has been performed for a sample of an oil-impregnated pressboard of the $X=4 \mathrm{wt} \%$ moisture content. Values of $\varepsilon^{\prime}(f)$ have been determined for the temperature of $293 \mathrm{~K}$ (Fig. 1) based on the measurement results given in (Ekanayake et al. 2006) and for the measuring temperatures of 323 and $353 \mathrm{~K}$ [Fig. 1 based on the measurement data given in Walczak et al. (2006)].
As can be seen in Fig. 1, in the ultra-low and lowfrequency areas, in an oil impregnated pressboard of the moisture content of $X=4 \mathrm{wt} \%$ the permittivity assumes values even higher than 1000. As it has been mentioned above, it is related, to the formation of electric dipoles resulting from the electron hopping exchange between nanoparticles of water. Along with the frequency increase up to approx. $f=10^{2} \mathrm{~Hz}$, the permittivity decreases. In the area of frequency values higher than $f=10^{2} \mathrm{~Hz}$, the permittivity remains constant.

It can be also seen in Fig. 1 that increasing the measuring temperature causes a shift of the $\varepsilon^{\prime}(f)$ characteristics to the higher frequency range. This effect results from the acceleration of relaxation processes in the pressboard along with the increasing temperature. In our opinion, this phenomenon can be taken into account by describing the relaxation time temperature changes with the use of the following formula (Psarras et al. 2003; Kudryashov et al. 2012):

$\tau(T)=\tau_{0} \exp \frac{\Delta E(\tau)}{k T}$,

where $\tau(T)$ relaxation time, $\tau_{0}$ numerical value, $\Delta E(\tau)$ activation energy of the relaxation time, $k$ Boltzmann constant, $T$ temperature.

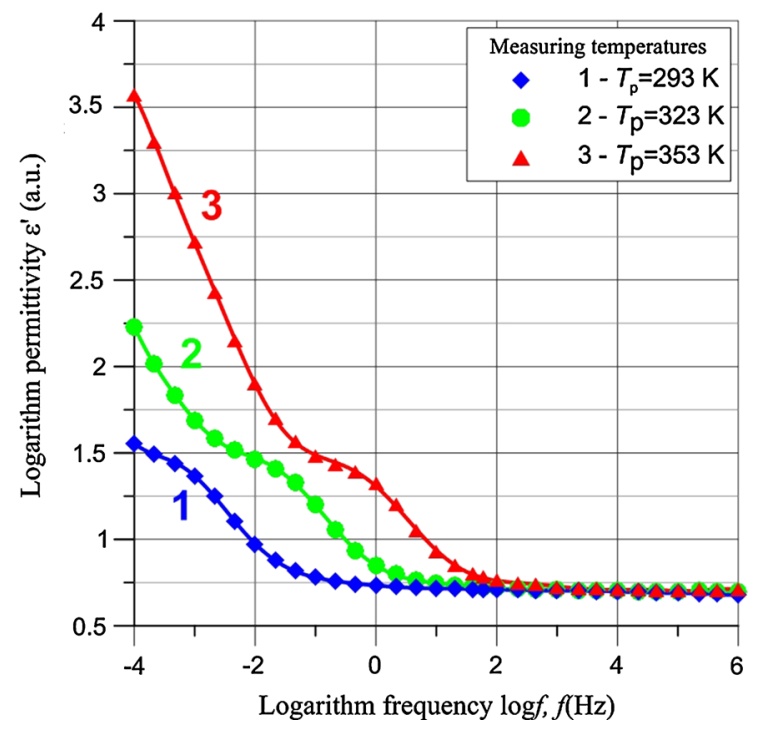

Fig. 1 Permittivity versus frequency $\varepsilon^{\prime}(f)$ for an impregnated pressboard of the $X=4 \mathrm{wt} \%$ water content. Calculations based on the data of Ekanayake et al. (2006), Walczak et al. (2006). Solid line approximation results 
In order to determine the relaxation time activation energy for the characteristics of Fig. 1, a characteristic point should be selected for each of the characteristics obtained at various temperatures. The best selection would be a natural point such as an extremum, whose shift could be easily controlled. As the experimental characteristics do not include such points, we have selected inflection points on the $\log \varepsilon^{\prime}$ in the function of $\log f$ curves to be used as reference points. In order to determine the inflection points, the frequency coefficient $\alpha(f)$ expressed by formula (Kołtunowicz et al. 2013; Svito et al. 2014):

$\alpha(f)=\frac{d\left(\log \varepsilon^{\prime}\right)}{d(\log f)}$

In inflection points the $\alpha(f)$ coefficient reaches its maximum $\alpha_{\max }(f)$ or its minimum $\alpha_{\min }(f)$ values. When the frequency value $f_{\max }$, at which the $\alpha\left(f_{\max }\right)=\alpha_{\max }(f)$ or $f_{\min }$, at which $\alpha\left(f_{\min }\right)=\alpha_{\min }(f)$ is taken as a reference point, it is possible to consider the temperature effect on the relaxation time $\tau$, given by the formula (6):

$$
\begin{aligned}
f_{\max }(T) \times \tau_{\max }(T)= & f_{\max }(T) \times \tau_{0 \max } \\
& \times \exp \frac{\Delta E\left(\tau, \varepsilon^{\prime}\right)}{k T}=\text { const } .
\end{aligned}
$$

By determining the $f_{\max }(T)$ value for two measuring temperatures $T_{1}$ and $T_{2}$ and comparing the formula (8) written for those temperatures, the relaxation time activation energy value can be obtained:

$\Delta E(\tau)=\frac{k}{\left(\frac{1}{T_{1}}-\frac{1}{T_{2}}\right)}\left(\ln f_{\max }\left(T_{2}\right)-\ln f_{\max }\left(T_{1}\right)\right)$.

Equations ( 8 and 9) can also be written for the values of $f_{\min }$ and $\tau_{\min }$.

As can be seen in Fig. 1, the experimentally determined measuring points are relatively sparsely distributed at the step of $\Delta \log f=0.333$. It follows from the fact that each measurement in the ultra-low frequency $\left(10^{-4}-10^{-3} \mathrm{~Hz}\right)$ area needs a long time to be completed. For that reason, when the $f_{\max }(T)$ value and consequently also the activation energy $\Delta E(\tau)$ values are determined directly from the experimental data, the determination accuracy is very low.

In order to enhance the determination accuracy for the $f_{\max }(T)$ values, a polynomial approximation procedure described in (Żukowski et al. 2015b) has been adapted to the permittivity testing purposes and applied to the experimental data.

Results of the polynomial approximation calculations of the permittivity versus frequency dependence are shown in Fig. 1 in the form of small dots that practically form solid lines.

Figure 1 also presents experimentally obtained data in the form of large points. As can be seen in the figure, a very good approximation has been obtained over the whole range of measuring frequencies. Figure 2 confirms that quality of the performed approximation by showing differences between the experimental data and the values obtained by means of the approximation. As can be seen in Fig. 2, the differences, do not exceed the value of 0.014 that is almost a hundred times lower than the experimental values (Fig. 1). The high quality of the approximation is also illustrated by the determination coefficient $R^{2}$, whose mean value, for the three measuring temperatures and the $X=4 \mathrm{wt} \%$ water level is $R^{2} \approx 0.99948$, which means that it approaches unity.

Values of frequency coefficients $\alpha(f)$ have been calculated based on the approximated characteristics $\varepsilon_{\mathrm{n}}^{\prime}(f)$ (Fig. 1) and using the Eq. (7)-Fig. 3.

Based on the characteristics shown in Fig. 3, the $f_{\max }(T)$ values have been determined to be used as reference points to calculate the relaxation time

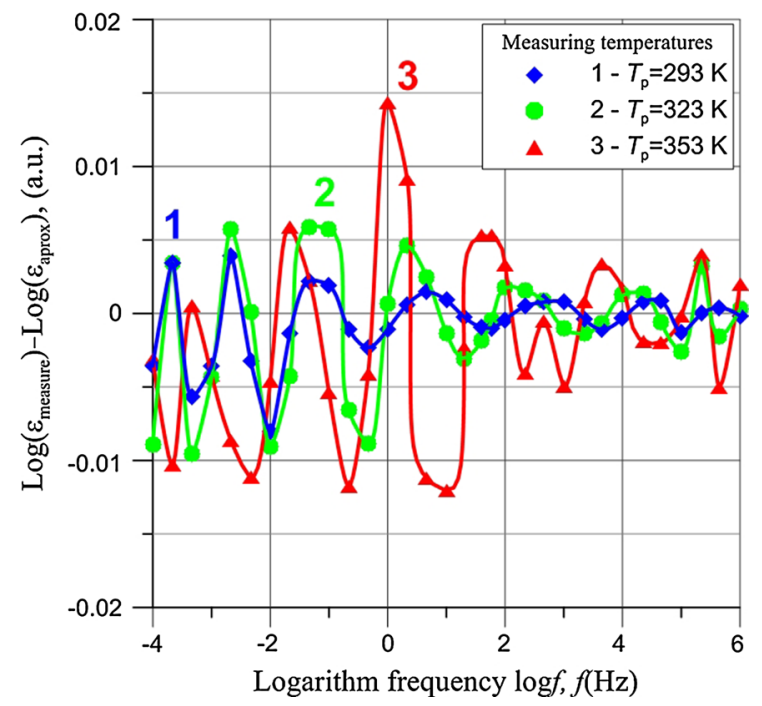

Fig. 2 Differences between experimental data and approximation results obtained for an impregnated pressboard of the moisture content of $X=4 \mathrm{wt} \%$ 
activation energy using the formula (9). The three available measuring temperatures have been used in three possible combinations of their pairs $\left(T_{1}-T_{2}, T_{2}-\right.$ $T_{3}, T_{1}-T_{3}$ ) to obtain the following three values of the activation energy: $\Delta E_{1}(\tau)=0.962 \mathrm{eV}, \quad \Delta E_{2}(-$ $\tau)=0.964 \mathrm{eV}, \Delta E_{3}(\tau)=0.951 \mathrm{eV}$. Mean value of the relaxation time activation energy for a pressboard of the $4 \mathrm{wt} \%$ water content has been of $\Delta E(\tau) \approx(0.959 \pm 0.0070) \mathrm{eV}$. Similar calculations have been performed for the activation energy and the determination coefficient $R^{2}$ of an oil-impregnated pressboard of the moisture content levels of 1,2 and $3 \mathrm{wt} \%$. Values of the activation energy, measurement uncertainty and the determination coefficient $R^{2}$ obtained for each of the moisture content levels as well as their mean values are shown in Table 1.

In the domain of electrical engineering, the temperature of $T_{0}=293.17 \mathrm{~K}\left(20^{\circ} \mathrm{C}\right)$ has been widely accepted as a reference temperature. Based on the obtained values of the relaxation time activation energy, the approximated values of $\varepsilon^{\prime}(f)$ (Fig. 1) have been converted to the reference temperature of $T_{0}=273.17 \mathrm{~K}\left(20^{\circ} \mathrm{C}\right)$.

Figure 4 presents approximated values of the relative permittivity of a composite of cellulose, mineral oil, and water nanoparticles of the $4 \mathrm{wt} \%$ moisture content obtained at the measuring

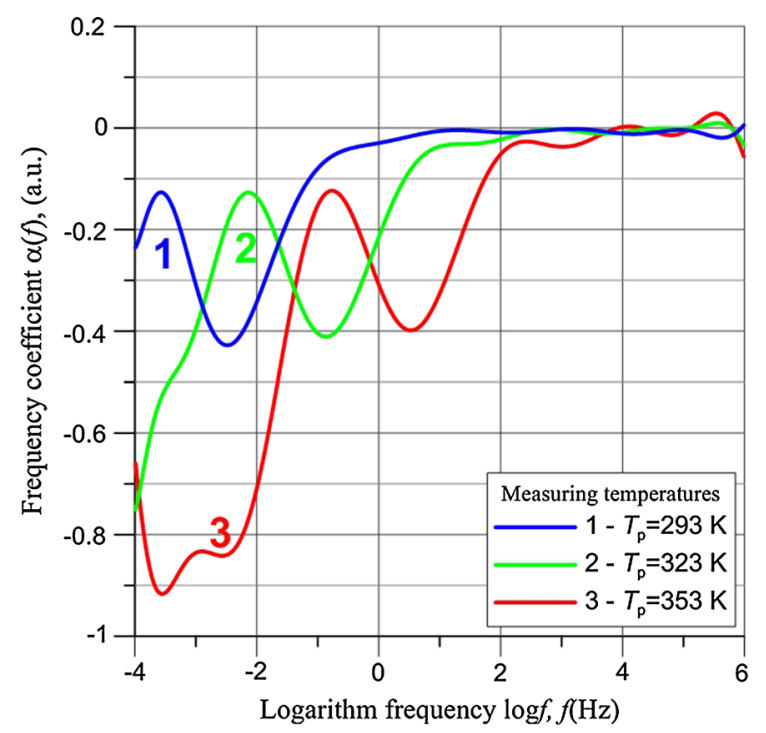

Fig. 3 Conductivity versus frequency dependences $\alpha(f)$ for an impregnated pressboard of the moisture content of $X=4 \mathrm{wt} \%$, calculated using the formula (7). Solid lines results of the polynomial approximation performed at the step of 0.01
Table 1 Values of the permittivity relaxation time activation energy and the measurement uncertainty for an oil-impregnated pressboard of the moisture content levels of $1,2,3$, and $4 \mathrm{wt} \%$

\begin{tabular}{llll}
\hline$X(\mathrm{wt} \%)$ & $\Delta E_{\mathrm{sr}}(\tau)(\mathrm{eV})$ & $\mathrm{u}\{\Delta E(\tau)\}(\mathrm{eV})$ & $\mathrm{R}^{2}$ (a.u.) \\
\hline 1 & 0.9302 & 0.0164 & 0.99956 \\
2 & 1.0410 & 0.0508 & 0.99982 \\
3 & 0.9939 & 0.0170 & 0.99971 \\
4 & 0.9590 & 0.0070 & 0.99948 \\
$1-4$ & 0.9810 & 0.0228 & 0.99964 \\
\hline
\end{tabular}

temperatures of $293,323,353 \mathrm{~K}$ and shifted to the reference temperature of $T_{0}=293.17 \mathrm{~K}\left(20^{\circ} \mathrm{C}\right)$ along the $x$-axis using earlier obtained values of the relaxation time activation energy $\Delta E(\tau)$. Figure 4 shows that owing to the shift of approximated curves along the horizontal axis by means of the relaxation time activation energy $\Delta E(\tau)$, perfect coincidence of characteristics obtained for various temperatures has been reached.

Figure 5 shows percentage differences between the curves obtained for the temperatures of 323 and $353 \mathrm{~K}$, shifted to the temperature of $293 \mathrm{~K}$ and referred to the approximation performed at the temperature of $293 \mathrm{~K}$ calculated using the below formula:

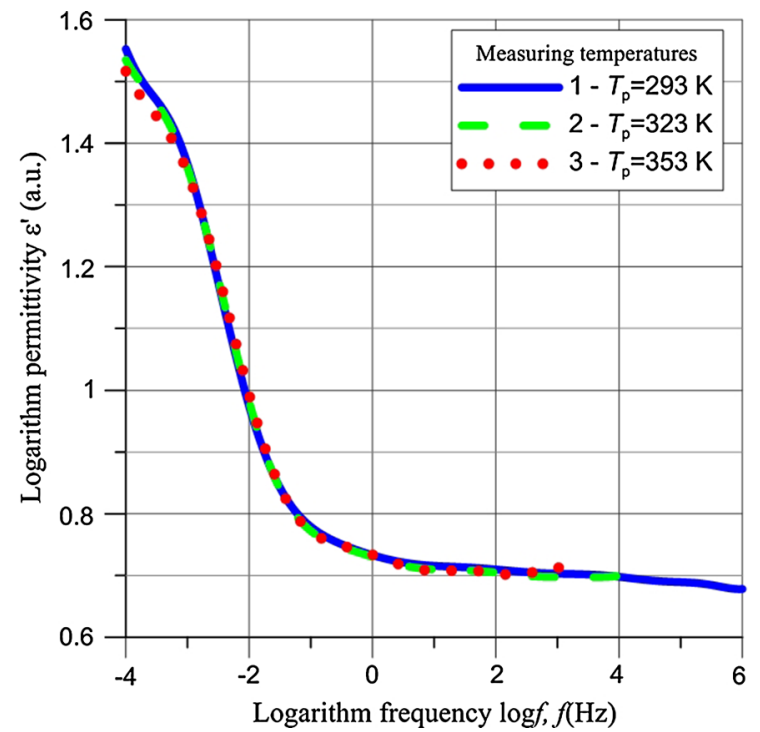

Fig. 4 Approximation of the permittivity versus frequency dependence for an impregnated pressboard of the water content of $X=4 \mathrm{wt} \%$. Shift along the horizontal axis to the reference temperature of $293 \mathrm{~K}$ 
$Y(\log f)=\frac{\varepsilon_{a p r}(293 \mathrm{~K})-\varepsilon_{a p r}\left(T_{i}\right)}{\varepsilon_{a p r}(293 \mathrm{~K})} \times 100 \%$

As can be seen in the Fig. 5, differences between the shifted curves for the temperatures of 323 and $353 \mathrm{~K}$ and the curve for the reference temperature of $293 \mathrm{~K}$, in the area of ultra-low frequencies, where polarization occurs resulting from the pressboard moisture, are lower than $2 \mathrm{wt} \%$, The difference value does not exceed the permittivity determination error. Figure 5 shows perfect coincidence of the characteristics obtained at various measuring temperatures and shifted to the reference temperature.

Conversion to the reference temperature of 293.17 K $\left(20^{\circ} \mathrm{C}\right)$ has been also performed on the permittivity versus frequency dependences obtained for a composite of cellulose, mineral oil, and water nanoparticles of the moisture content levels of 1,2 and $3 \mathrm{wt} \%$, at the measuring temperatures of 293, 323, $353 \mathrm{~K}$. The calculation results are shown in Fig. 6. Figure 6 shows perfect coincidence of the relative permittivity characteristics obtained at various temperatures for each of the mentioned moisture content values. The curves shown in Figs. 4 and 6, at the left side have been reduced to the value of $\log f=-4$. It follows from the fact that, when the curves for

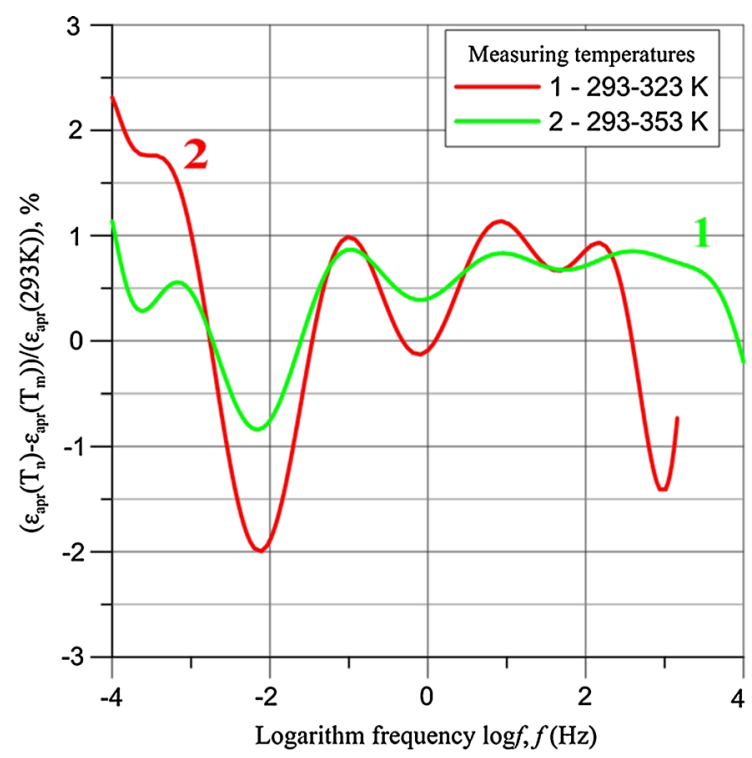

Fig. 5 Percentage differences between values obtained by approximation shifted to the temperature of $293 \mathrm{~K}$ for the measuring temperatures referred to the approximated curve for the temperature of $293 \mathrm{~K}$
$T=323$ and $353 \mathrm{~K}$ are shifted to the reference temperature of $293 \mathrm{~K}$, below the $\log f=-4$ value there is no characteristic for the temperature of $T_{0}=293.17 \mathrm{~K}\left(20^{\circ} \mathrm{C}\right)$ that makes a reference curve for the ones obtained for higher temperatures.

As can be seen in Fig. 1, distinct temperature dependences occur for the permittivity versus frequency characteristics plotted based on the measurement results. Figures 4 and 6 shows that the developed method for the conversion of $\varepsilon^{\prime}(f)$ characteristics obtained for any measuring temperature to the reference temperature of $T_{0}=273.17 \mathrm{~K}\left(20{ }^{\circ} \mathrm{C}\right)$ eliminates the temperature effect of on them. It means that a shape of the $\varepsilon^{\prime}(f)$ curve obtained for a composite of cellulose, mineral oil, and water nanoparticles depends solely on the moisture content level, while its position on the frequency axis is a function of the relaxation time.

Another important observation (see Table 1) is that the relaxation time activation energy does not depend on the moisture content. Similar results have been previously obtained for the DC conductivity in (Żukowski et al. 2015a), and for the AC conductivity and the conductivity relaxation time-in (Żukowski et al. 2015b).

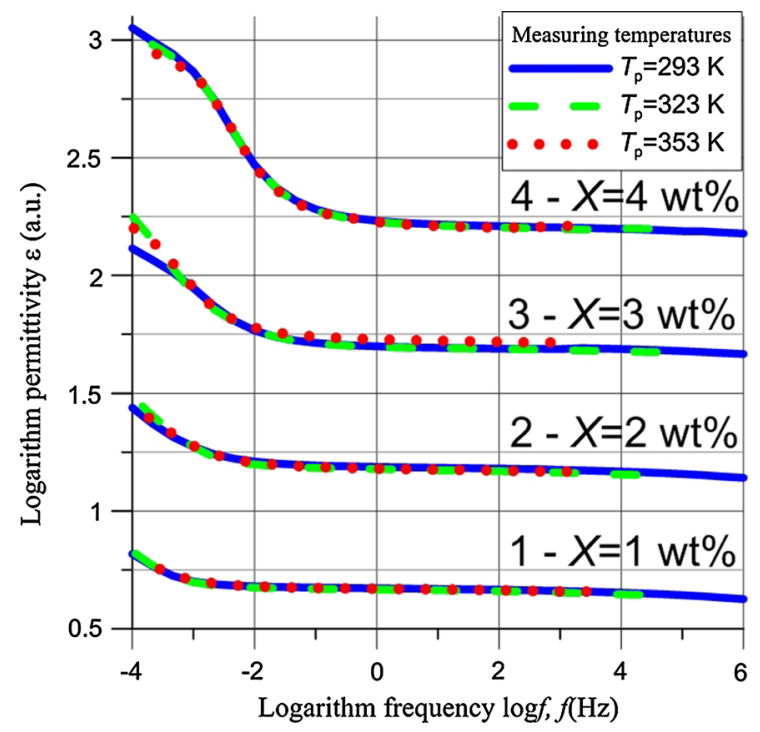

Fig. 6 Approximation of the permittivity versus frequency dependence $\varepsilon^{\prime}(f)$ for an impregnated pressboard of the water content levels of $1-X=1 \mathrm{wt} \%, 2-X=2 \mathrm{wt} \%, 3-$ $X=3 \mathrm{wt} \%, 4-X=4 \mathrm{wt} \%$. Shift along the horizontal axis to the reference temperature of $293.17 \mathrm{~K}\left(20^{\circ} \mathrm{C}\right)$. Curves $2-4$ are shifted along the $y$ axis by $0.5,1.0$, and 1.5 , respectively 
The relaxation time activation energy is a function of two energy states of a hopping electron-its initial energy state in the neutral well, wherefrom hops and its energy state in the well, whereto it has hoped. Additionally, there is the potential energy of a dipole that forms as a result of that electron hop. As the potential energy value for a dipole of approx. $10 \mathrm{~nm}$ is on the order of $10 \mathrm{meV}$, its effect on the relaxation time activation energy, whose value is of approx. $0.98 \mathrm{eV}$, is negligible (see: energy activation values in Table 1). It means that the moisture content changes do not affect energy states of electrons in potential wells nor the structure of water nanoparticles forming the wells.

Once the conversion to the reference temperature of $T_{0}=293.17 \mathrm{~K}\left(20^{\circ} \mathrm{C}\right)$ has been performed on the permittivity versus frequency curve obtained for a composite of cellulose, mineral oil, and water nanoparticles, it is only the dependence on the moisture content that occurs (Fig. 6).

In our opinion, the above can be used as a basis for the development of a new method for determining a water content level in a paper-oil insulation used in power transformers.

\section{Conclusions}

An analysis of the relative permittivity dependences on frequency obtained for a composite of cellulose, mineral oil, and water nanoparticles, measured at different temperatures, has shown that increase of the temperature not changes the shape of the waveform but only causes a shift to higher frequency value. This means that in the whole frequency range of $10^{-4}-10^{6} \mathrm{~Hz}$ permittivity is described by the same value of the relaxation time, which is the exponential function of temperature.

It was found, that the content variations moisture in a composite of cellulose, mineral oil, and water nanoparticles do not affect values of the relaxation time activation energy, the electron energy states in potential wells nor the structure of water nanoparticles. Also determined was the value of the energy activation relaxation time, which value is $\Delta \mathrm{E}(\tau) \approx$ $(0.981 \pm 0.0228) \mathrm{eV}$.

It has been found that in the low frequency area, where relaxation related to water molecules occurs, experimental curves obtained with the FDS method reach full coincidence, when shifted along the horizontal axis with the use of the relaxation time activation energy $\Delta E(\tau)$.

The new method for converting the experimentally obtained permittivity versus frequency dependence for a composite of cellulose, mineral oil, and water nanoparticles to the reference temperature of 293.17 $\mathrm{K}\left(20{ }^{\circ} \mathrm{C}\right)$, has made possible to eliminate temperature dependences that occur in the characteristics based on measurement results. When data concerning the pressboard relative permittivity are converted to the reference temperature, the only permittivity dependence that is left is that on the moisture content level. It can be a basis for the development of a new method for the determination of the water content level in paperoil insulation in power transformers.

Open Access This article is distributed under the terms of the Creative Commons Attribution 4.0 International License (http:// creativecommons.org/licenses/by/4.0/), which permits unrestricted use, distribution, and reproduction in any medium, provided you give appropriate credit to the original author(s) and the source, provide a link to the Creative Commons license, and indicate if changes were made.

\section{References}

Cole KS, Cole RH (1941) Dispersion and absorption in dielectrics-I. Alternating current characteristics. J Chem Phys 9(341):341-352. doi:10.1063/1.1750906

Cole KS, Cole RH (1942) Dispersion and absorption in dielectrics-II. Direct current characteristics. J Chem Phys 10(98):98-105. doi:10.1063/1.1723677

Dey D, Chatterjee B, Chakravorti S, Munshi S (2010) Importance of denoising in dielectric response measurements of transformer insulation: an uncertainty analysis based approach. Measurement 43(1):54-66

Ekanayake C, Gubanski SM, Graczkowski A, Walczak K (2006) Frequency response of oil impregnated pressboard and paper samples for estimating moisture in transformer insulation. IEEE Trans Power Deliv 21(3):1309-1317

Gilbert R, Jalbert J, Duchesne S, Tétreault P, Morin B, Denos Y (2010) Kinetics of the production of chain-end groups and methanol from the depolymerization of cellulose during the ageing of paper/oil systems. Part 2: thermally-upgraded insulating papers. Cellulose 17(2):253-269

Halliday D, Resnick R (1978) Physics, part II. Wiley, New York

Havriliak S Jr, Havriliak SJ (1997) Dielectric and mechanical relaxation in materials. Analysis, interpretation and application to polymers. Hanser, Munich

Jalbert J, Rodriguez-Celis E, Duchesne S, Morin B, Ryadi M, Gilbert R (2015) Kinetics of the production of chain-end groups and methanol from the depolymerization of cellulose during the ageing of paper/oil systems. Part 3: extension of the study under temperature conditions over 
$120^{\circ} \mathrm{C}$. Cellulose 22(1):829-848. doi:10.1007/s10570014-0516-8

Jaya M, Geißler D, Leibfried T (2013) Accelerating dielectric response measurements on power transformers-part I: a frequency-domain approach. IEEE Trans Power Deliv 28(3):1469-1473

Jonscher AK (1983) Dielectric relaxation in solids. Chelsea Dielectrics Press, London

Kołtunowicz TN, Fedotova JA, Zhukowski P, Saad A, Fedotov A, Kasiuk JV, Larkin AV (2013) Negative capacitance in (FeCoZr)-(PZT) nanocomposite films. J Phys D Appl Phys 46(12):125304

Kudryashov MA, Mashin AI, Logunov AA, Chidichimo G, De Filpo G (2012) Frequency dependence of the electrical conductivity in Ag/PAN nanocomposites. Tech Phys 57(7):965-970

Landau LD, Lifshitz EM, Pitaevskii LP (1984) Electrodynamics of continuous media. Butterworth-Heinemann, Oxford

Oommen TV (1983) Moisture equilibrium in paper oil systems. In: Proceedings of the 16th electrical/electronics insulation conference, October 3-6, Chicago, IL, USA, pp 162-166

Pogrebnjak AD, Beresnev VM (2012) Nanocoatings, nanosystems, nanotechnologies. Bentham Science, Oak Park

Pogrebnyak AD, Kaverina ASh, Kylyshkanov MK (2014) Electrolytic plasma processing for plating coatings and treating metals and alloys. Prot Met Phys Chem Surf 50(1):74-89

Psarras GC, Manolakaki E, Tsangaris GM (2003) Dielectric dispersion and ac conductivity in iron particles loaded polymer composites. Compos Part A Appl Sci Manuf 34(12):1187-1198

Ralchenko VG, Karkin AE, Khomich AV, Poklonski NA, Vlasov II, Khomich AA, Shiryaev AV, Popovich AF, Klokov AYu, Sharkov AI, Aminev DF, Poklonskaya ON, Gorbachuk NI (2012) Structure, optical, electrical, thermal and acoustical properties of neutron irradiated CVD diamond. In: Grigonis A (ed) Book series radiation interaction with material and its use in technologies, Kaunas Univ Technology Press, Kaunas, pp 342-345

Saha T (2003) Review of Time-domain polarization measurements for assessing insulation condition in aged transformers. IEEE Trans Power Deliv 18(4):1293-1300

Saha TK, Purkait P (2004) Investigation of polarization and depolarization current measurements for the assessment of oil-paper insulation of aged transformers. IEEE Trans Dielectr Electr Insul 11(1):144-154

Svito I, Fedotov AK, Koltunowicz TN, Zhukowski P, Kalinin Y, Sitnikov A, Czarnacka K, Saad A (2014) Hopping of electron transport in granular $\mathrm{Cu}_{\mathrm{x}}\left(\mathrm{SiO}_{2}\right)_{1-\mathrm{x}}$ nanocomposite films deposited by ion-beam sputtering. J Alloy Compd 615(1):S371-S374

US Department of the Interior Bureau of Reclamation (2003) Facilities instructions, standards and techniques, vols 3-31, "transformer diagnostics". US Department of the Interior Bureau of Reclamation, Washington, DC

Walczak K, Graczkowski A, Gielniak J, Morańda H, MościckaGrzesiak H, Ekanayake C, Gubański S (2006) Dielectric frequency response of cellulose samples with various degree of moisture content and aging. Prz Elektrotech 1:264-267 (in Polish)

Wolny S, Kedzia J (2010) The assessment of the influence of temperature of selected parameters of the approximation method of depolarization current analysis of paper-oil insulation. J Noncryst Solids 356(11-17):809-814

Zhang T, Li X, Lv H, Tan X (2014) Parameter identification and calculation of return voltage curve based on FDS data. IEEE Trans Appl Supercond 24(5):9002405

Zukowski PW, Kantorow SB, Kiszczak K, Maczka D, Stelmakh VF, Rodzik A, Czarnecka-Such E (1991) Study of dielectric function of silicon irradiation with great dose of neutrons. Phys Status Solidi A 128(2):K117-K121

Zukowski PW, Rodzik A, Shostak YA (1997) Dielectric constant and AC conductivity of semi-insulating $\mathrm{Cd}_{1-\mathrm{x}} \mathrm{MnxTe}$ semiconductors. Semiconductors 31(6):610-614

Żukowski P, Kołtunowicz TN, Kierczyński K, Subocz J, Szrot M, Gutten M (2014) Assessment of Water content in an impregnated pressboard based on DC conductivity measurements. Theoretical assumptions. IEEE Trans Dielectr Electr Insul 21(3):1268-1275

Żukowski P, Kołtunowicz TN, Kierczyński K, Subocz J, Szrot M (2015a) Formation of water nanodrops in cellulose impregnated with insulating oil. Cellulose 22(1):861-866. doi:10.1007/s10570-015-0543-0

Żukowski P, Kołtunowicz TN, Kierczyński K, Subocz J, Szrot M, Gutten M, Sebok M, Jurcik J (2015b) An analysis of AC conductivity in moist oil-impregnated insulation pressboard. IEEE Trans Dielectr Electr Insul 22(4):2156-2164 